\title{
EVALUATION OF CORNEAL ENDOTHELIAL CELLS AFTER PARS PLANA VITRECTOMY
}

\section{Sara Fawzy Ibrahim, Hassan Ali Zaki, Sherif Abbas Dabour, Ashraf Mahrous Eid}

Corresponding author:

Ophthalmology department, Faculty of medicine, Zagazig University, Egypt

ABSTRACT
Background: The corneal complications of vitreo-retinal surgery are rarely the primary concern of the surgeon operating on a difficult retinal detachment. However, the surgeon should be aware of which procedures are more likely to induce corneal decompensation, because corneal abnormalities are a common cause of visual loss following an otherwise successful surgery ${ }^{[1]}$. Thus it is important to evaluate corneal endothelial cell changes after PPV.

Aim of the work: To evaluate corneal endothelial cell changes in patients undergoing Pars plana vitrectomy with silicone oil (SO) injection.

Subjects and Methods: This prospective comparative observational study evaluated the corneal endothelial cell characteristics of 27 SO filled vitrectomizied eyes operated in Zagazig University Hospitals, Ophthalmology department. Endothelial cell densities (ECD), coefficient of variation (CV), central corneal thickness (CCT) and percentage of hexagonal cells (hexagonality) at the corneal center were measured preoperatively, 1 week, 1 month and 3 months after surgery using noncontact specular microscopy and were compared pre and post operatively. Exclusion criteria were previous vitreoretinal surgery, aphakia, any degree of anterior chamber inflammation, history of previous eye trauma, SO bubbles in the anterior chamber and increased intraocular pressure in the postoperative period.

Results: Three months after pars plana vitrectomy with silicone oil injection, mean ECD was $2032.92 \pm 434.41$ cells $/ \mathrm{mm}^{2}$ in the vitrectomized eyeswhile mean hexagonality (pleomorphism) was $65.66 \pm 8.05$. Three months after operation, CV (polymegathism) was $31.03 \pm 5.97$ while mean CCT was $552.51 \pm 32.01 \mu \mathrm{m}$ with no corneal edema reported at the end of the study.

Conclusion: Although the presence of SO in the vitreous cavity, PPV was associated with corneal endothelial cell changes in the form of EC loss and pleomorphism. Silicone oil could be a risk factor for increasing endothelial cell loss after pars plana vitrectomy. The percentage of corneal endothelial cell loss was higher in patients with SO injection than those left saline filled, but it was statistically insignificant Thus, removal of SO after reaching the desired tamponade effect is recommended.

Keywords: Corneal Endothelial Cells; Pars Plana Vitrectomy; Phakic Eyes; Pseudophakic Eyes; Silicone Oil; Specular Microscopy.

\section{INTRODUCTION}

$\mathbf{P}$ ars plana vitrectomy (PPV) is a surgical procedure that involves removal of vitreous gel from the eye to provide better access to the retina. PPV was developed by Robert Machemer in $1970^{[2]}$. The main indications of PPV include rhegmatogenous or tractional retinal detachment,vitreous hemorrhage, retained lens fragments after cataract surgery, endophthalmitis, epiretinal membrane,macular hole, vitreomacular traction and intraocular foreign bodies ${ }^{[3]}$. PPV may be contraindicated if the eye has no light perception and if regaining any vision in the eye is impossible. Vitrectomy is contraindicated in the presence of suspected or active retinoblastoma or active choroidal melanoma for fear of systemic seeding following incisions ${ }^{[4]}$.

The introduction of materials into the posterior segment of the eye as a surgical adjunct dates back to the earlies of the 20th century, with the introduction of air into the vitreous cavity by $\mathrm{Ohm}$. Over time, a variety of compounds have been adapted for use in the eye. Following vitrectomy, a vitreous substitute is injected into the eye to maintain 
Sara et al..

the retina in position. Vitreous substitutes in common use include air, saline, sulfur.

hexafluoride gas (SF6), n-perfluoropropane gas $(\mathrm{C} 3 \mathrm{~F} 8)$ and silicone oil $(\mathrm{SO})^{[5]}$.

Silicone oil has been used as an internal tamponade for complex retinal detachment since $1962^{[6]}$. SO is available in various viscosities; 1000, 1300, 2000, 5000 and 5500 centistokes. The $1000 \mathrm{cs}$ silicone is easy to inject and to remove while $5000 \mathrm{cs}$ silicone is less prone to emulsification ${ }^{[7]}$. It is a common practice to remove SO after a period of time to reduce its complications; such as cataract, glaucoma and corneal decompensation ${ }^{[8]}$.

Corneal endothelial cell (EC) loss can result from both intrinsic factors, such as trauma, ocular surgery, systemic diseases (as diabetes) and ultraviolet radiation, and extrinsic factors, such as age, race, gender, and genetics [9]. As an intraocular surgery, vitreoretinal surgery is associated with EC changes. During surgery, factors as intraocular irrigation solution and operation time may affect the corneal endothelium. Also, furthermore damage may be related to the used tamponade ${ }^{[10]}$.

The mechanism by which silicone oil causes corneal endothelial damage remains controversial. Many studies reported that it has been related to emulsification causing small silicone droplets to liberate from the large silicone bubble and to diffuse into the anterior chamber ${ }^{[11]}$. A direct destructive "barrier effect" "with solubilization of the cell membrane or a mechanical prevention of nutrients reaching the corneal endothelial cells may also be of importance ${ }^{[12] \&[13]}$.

It was hypothesized that the adverse effects of SO on the cornea are related to direct contact of SO with cornea. However, studies have focused on the corneal endothelial cells damage in the presence of $\mathrm{SO}$ in the vitreous cavity without direct corneal touch $^{[14]}$. It was believed that even with intact iris-lens diaphragm, there was possibility of SO toxicity on corneal endothelium $^{[10]}$. Damage to endothelial cells may lead to stromal edema which ranges from striate keratopathy to deep corneal edema, clouding and decompensation $^{[\mathbf{1 5 ]}}$.

The cornea's refracting surface is responsible for about two thirds of the refractive power of the eye and plays an important role in focusing images on the retina. This function can be defined in terms of corneal shape, regularity, clarity and the refractive index, all of which might be susceptible to intraoperative compromise after vitreoretinal surgery ${ }^{[16]}$. However, even after successful retinal reattachment, postoperative vision may be unsatisfactory for the patient in some cases due to corneal complications that might persist after surgery ${ }^{[17]}$.

That's why a pre-operative clinical estimate of ECs using specular microscopy can provide data regarding ECD and morphology, thus facilitating assessment of the functional reserve of the endothelium in individual patients. This analysis provides a measure of the general health of the corneal endothelium, which is important before any intraocular surgery and provide a baseline to predict post-operative outcomes of corneal state that influence patients' visual outcomes $^{[10]}$.

\section{SUBJECTS AND METHODS}

Study design and population:

- This isa prospective comparative observational study on 27Patients collected from the outpatient clinics of Ophthalmology Department Zagazig University Hospital.The 27 patients (27 eyes) were scheduled for pars plana vitrectomy surgery at the Ophthalmology Department, Zagazig University Hospitals, in the period between March and November 2017. Patients were operated for pars plana vitrectomy with silicone oil injection.

Inclusion Criteria:

- Adult patients aged above 40 years old.

- Phakic prepared for pars plana vitrectomy

- pseudophakic patients, in whom cataract surgery was done at least 6 months before and have intact posterior lens capsule, prepared for pars plana vitrectomy

- Patients with preoperative endothelial cell count more than 2000 cells $/ \mathrm{m}^{\mathrm{m} 2}$

Exclusion Criteria:
- Pre-existing abnormalities
- Previous ocular inflammations
- Previous ocular trauma
- Glaucoma 
- Patients with zonular dehiscence

- Patients with sublaxation.

- Patients scheduled for phacovitrectomy will be excluded .

- Patients performing any anterior segment procedures during follow up will be excluded

Ethical consideration:

Consent was obtained from every patient after explanation of the procedure. Medical research and ethics committee approved the study.

Data collection:

Preoperatively, complete ophthalmic examinations were performed to all patients including the following: history, visual acuity, slit lamp examination, IOP measurement, fundus examination and imaging of the corneal endothelium by noncontact specular microscope (NIDEK CEM-530, Ltd., gamagori, Japan) to assess [endothelial cell density (ECD), central corneal thickness (CCT), Coefficient of Variation (CV) and Hexagonal cells (HEX)].

20-gauge pars plana vitrectomy PPV was done depending on the reason for the vitrectomy with endotamponade silicone oil (silicone $5000 \mathrm{cSt}$ ).

Intraoperative events were recorded during surgery including total irrigation volume used, operation time, and intraoperative complications.

Regular postoperative follow-up was conducted on $7^{\text {th }}$ day, $1^{\text {st }}$ month, $3^{\text {rd }}$ month with special attention to slit-lamp examination (corneal state),intraocular pressure ( IOP), visual acuity and imaging of corneal endothelium by Nidek CEM-530 noncontact specular microscope for assessment of endothelial cell parameters mentioned before.

\section{RESULTS:}

Table (1): Demographic data of the studied patients $(\mathrm{N}=27)$.

\begin{tabular}{|c|c|c|}
\hline \multirow{2}{*}{ Variables } & \multicolumn{2}{|c|}{ Silicone (SO) } \\
\cline { 2 - 3 } & \multicolumn{2}{|c|}{$54.6 \pm 8.7$} \\
\hline Age & 13 & 48.1 \\
\hline Sex & 14 & 51.9 \\
\hline Male & 11 & 40.7 \\
\hline female & 16 & 59.3 \\
\hline DM* & \multicolumn{2}{|c|}{} \\
\hline Yes & 17 & 63.0 \\
\hline No & 10 & 37.0 \\
\hline Laterality & & \\
\hline OD & N & \\
\hline OS & \multicolumn{2}{|c|}{} \\
\hline
\end{tabular}

* DM: Diabetes Mellites

Table (2): Preoperative assessment of all patients.

\begin{tabular}{|c|c|c|}
\hline \multirow{2}{*}{ Variable } & \multicolumn{2}{|c|}{ Silicone(SO) } \\
\cline { 2 - 3 } & $\mathbf{N}$ & \% \\
\hline BCVA & 0 & $0.00 \%$ \\
\hline 1160 & 6 & $22.20 \%$ \\
\hline CF $30 \mathrm{~cm}$ & 0 & $0.00 \%$ \\
\hline CF 50 cm & 0 & \\
\hline
\end{tabular}




\begin{tabular}{|c|c|c|}
\hline HMBP & 7 & $25.90 \%$ \\
\hline HMGP & 10 & $37.00 \%$ \\
\hline PLGP & 4 & $14.80 \%$ \\
\hline Lens status & 17 & $63.00 \%$ \\
\hline phakic & 10 & $37.00 \%$ \\
\hline pseudophakic & 27 & $100 \%$ \\
\hline Corneal clarity & \multicolumn{2}{|}{} \\
\hline Clear & \multicolumn{2}{|c|}{$13.6 \pm 2.4^{*}$} \\
\hline IOP & \multicolumn{2}{|c|}{} \\
\hline &
\end{tabular}

Table (3): Preoperative specular data of the studied patients $(\mathrm{N}=27)$.

\begin{tabular}{|c|c|}
\hline \multirow{2}{*}{ Variables } & Silicone $(\mathrm{N}=27)$ \\
\cline { 2 - 2 } & Mean \pm sd \\
\hline ECD $\left(\right.$ cells $\left./ \mathrm{mm}^{2}\right)$ & $2751.25 \pm 442.75$ \\
\hline CV $(\boldsymbol{\%})$ & $29.48 \pm 5.08$ \\
\hline HEX $(\%)$ & $69.48 \pm 4.89$ \\
\hline CCT $(\mu \mathrm{m})$. & $555.40 \pm 47.60$ \\
\hline
\end{tabular}

Fig 1: Posterior segment problems in silicone filled patients

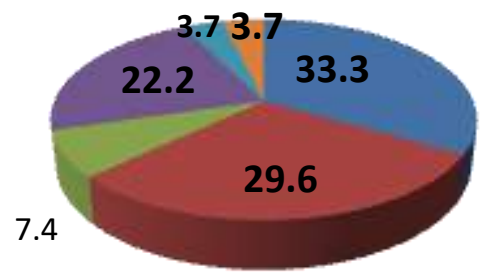
pseudophakic RD
- RRD
- Tractional RD
combined RD
- Giant tear
Macular hole

Table (4): Operative data of the studied patients.

\begin{tabular}{|c|c|c|c|c|}
\hline \multirow{2}{*}{ variable } & \multicolumn{2}{|c|}{ Silicone $(\mathrm{SO})$} & $\mathrm{t}$ test & \multirow{2}{*}{$\mathrm{p}$ value } \\
\cline { 2 - 4 } & Mean \pm sd & Min-max & & \\
\hline Duration/min & $47.44 \pm 6.7$ & $(35.0-59.0)$ & 3.15 & $0.003^{*}$ \\
\hline $\begin{array}{c}\text { Irrigation Volume } \\
/ \mathrm{ml}\end{array}$ & $356.67 \pm 42.0$ & $(280-420.0)$ & 2.4 & $0.023^{*}$ \\
\hline
\end{tabular}

Table (5): IOP assessment during the study.

\begin{tabular}{|l|l|c|}
\hline \multicolumn{1}{|c|}{$\begin{array}{c}\text { IOP } \\
(\mathrm{mmHg})\end{array}$} & \multicolumn{1}{|c|}{$\begin{array}{c}\text { Silicone } \\
(\mathrm{G} 1)\end{array}$} & \\
\hline preoperative & $13.55 \pm 2.39$ & $2.45 \pm 0.73$ \\
\hline 1 week & $15.82 \pm 1.24$ & \\
\hline 1 month & $16.14 \pm 1.53$ & \\
\hline 3 months & $16.00 \pm 1.66$ & \\
\hline $\mathrm{P}$ & $<0.001 * *$ & \\
\hline
\end{tabular}


Sara et al.. Zagazig University Medical Journals

Table (6): Mean ECD preoperatively, 1 week, 1 month and 3months postoperatively.

\begin{tabular}{|l|l|c|}
\hline \multicolumn{1}{|c|}{$\begin{array}{c}\text { ECD } \\
\left(\text { cells } / \mathrm{mm}^{2}\right)\end{array}$} & \multicolumn{1}{|c|}{ Mean values } & Mean change silicone \\
\hline \multicolumn{1}{|c|}{ preoperative } & $2751.25 \pm 442.75$ & $718.33 \pm 8.34$ \\
\hline 1 week & $2418.85 \pm 453.47$ & \\
\hline 1 month & $2246.59 \pm 483.76$ & \\
\cline { 1 - 2 } months & $2032.92 \pm 434.41$ & \\
\hline P & $<0.001 * *$ & \\
\hline
\end{tabular}

$P$ : Difference within time in the group

** P-value $<0.001$ is highly significant

Table (7):Percent of EC loss from the base over the 3-months follow-up period.

\begin{tabular}{|l|l|c|c|}
\hline \multicolumn{1}{|c|}{$\begin{array}{c}\text { ECD } \\
\left(\text { cells/mm } \mathbf{~}^{2}\right)\end{array}$} & $\begin{array}{c}\text { Silicone } \\
(\text { Mean } \pm \text { sd) }\end{array}$ & $\begin{array}{c}\text { Percent of EC loss from } \\
\text { baseline silicone (SO) }\end{array}$ & P \\
\hline preoperative & $2751.25 \pm 442.75$ & --- & $<0.001^{* *}$ \\
\hline 1 week & $2418.85 \pm 453.47$ & $12 \%$ & \\
\hline 1 month & $2246.59 \pm 483.76$ & $18.34 \%$ & \\
\hline 3 months & $2032.92 \pm 434.41$ & $26.1 \%$ & \\
\hline
\end{tabular}

Table (8): Changes in CV before and after surgery.

\begin{tabular}{|l|l|c|}
\hline \multicolumn{1}{|c|}{$\begin{array}{c}\text { CV } \\
(\%)\end{array}$} & \multicolumn{1}{|c|}{ Mean values } & Mean change \% \\
\hline preoperative & $29.48 \% \pm 5.08 \%$ & \multirow{2}{*}{$1.55 \pm 0.89$} \\
\hline 1 week & $29.81 \% \pm 6.15 \%$ & \\
\hline 1 month & $31.22 \% \pm 6.77 \%$ & \\
\hline 3 months & $31.03 \% \pm 5.97 \%$ & \\
\hline P & 0.55 & \\
\hline
\end{tabular}

Table (9): Changes in HEX before and after surgery.

\begin{tabular}{|l|l|l|}
\hline HEX (\%) & \multicolumn{1}{|c|}{ Mean values } & \multirow{2}{*}{ Mean change \% } \\
\cline { 1 - 2 } preoperative & $69.48 \pm 4.89$ & \multirow{2}{*}{$3.82 \pm 4.5$} \\
\hline 1 week & $71.15 \pm 4.24$ & \\
\hline 1 month & $67.37 \pm 6.98$ & \\
\hline 3 months & $65.66 \pm 8.05$ & \\
\hline P1 & $0.005 *$ & \\
\hline
\end{tabular}


Sara et al.. Zagazig University Medical Journals

Table (10): Changes in CCT before and after surgery

\begin{tabular}{|l|l|c|}
\hline \multicolumn{1}{|c|}{$\begin{array}{c}\text { CCT } \\
(\boldsymbol{\mu m})\end{array}$} & \multicolumn{1}{|c|}{ Mean values } & Mean change \\
\hline \multicolumn{1}{|c|}{ preoperative } & \multicolumn{1}{|c|}{$555.40 \pm 47.60$} & $3.25 \pm 24.59$ \\
\hline 1 week & $548.81 \pm 40.76$ & \\
\hline 1 month & $547.22 \pm 36.00$ & \\
\hline 3 months & $552.51 \pm 32.01$ & \\
\hline P & 0.773 & \\
\hline
\end{tabular}

P: Difference within time in the group $\quad * * P$-value $<0.001$ is highly significant

Table (11):ECD changes according to lens status.

\begin{tabular}{|c|c|c|c|c|c|}
\hline $\begin{array}{c}\text { ECD } \\
\left.\text { (cells } / \mathrm{mm}^{2}\right)\end{array}$ & Phakic & PseudoPhakic & $\begin{array}{l}\text { Mean percent } \\
\text { change (Phakic) }\end{array}$ & $\begin{array}{l}\text { Mean percent } \\
\text { change } \\
\text { (Pseudophakic) }\end{array}$ & $\mathrm{F}$ \\
\hline preoperative & $2640.81 \pm 327.57$ & $2771.63 \pm 419.75$ & \multirow{4}{*}{$\begin{array}{c}605.3 \pm 41.50 \\
(21.8 \%)\end{array}$} & \multirow{4}{*}{$\begin{array}{c}448.5 \pm 133.23 \\
(17 \%)\end{array}$} & \multirow[t]{4}{*}{144.98} \\
\hline 1 week & $2557.89 \pm 341.78$ & $2529.87 \pm 435.07$ & & & \\
\hline 1 month & $2335.04 \pm 427.77$ & $2354.64 \pm 395.40$ & & & \\
\hline 3 months & $2192.86 \pm 460.80$ & $2166.33 \pm 460.80$ & & & \\
\hline $\mathrm{P} 1$ & \multicolumn{5}{|l|}{$<0.001 * *$} \\
\hline $\mathrm{P} 2$ & \multicolumn{5}{|l|}{0.598} \\
\hline
\end{tabular}

Table (12): ECD changes in diabetic and non-diabetic patients.

\begin{tabular}{|c|c|c|c|c|c|}
\hline $\begin{array}{c}\mathrm{ECD} \\
\left(\text { cells } / \mathrm{mm}^{2}\right)\end{array}$ & Diabetic & Non diabetic & $\begin{array}{c}\text { Mean percent } \\
\text { change } \\
\text { Diabetic }\end{array}$ & $\begin{array}{l}\text { Mean percent } \\
\text { change } \\
\text { Non diabetic }\end{array}$ & $\mathrm{F}$ \\
\hline preoperative & $2671.26 \pm 408.45$ & $2770.26 \pm 368.68$ & \multirow[t]{4}{*}{$-532.52 \pm 12.3$} & \multirow[t]{4}{*}{$-555.7 \pm 56.44$} & \multirow[t]{4}{*}{189.61} \\
\hline 1 week & $2470.44 \pm 410.63$ & $2506.30 \pm 403.98$ & & & \\
\hline 1 month & $2311.74 \pm 415.91$ & $2382.30 \pm 397.12$ & & & \\
\hline 3 months & $2138.74 \pm 420.48$ & $2214.56 \pm 425.12$ & & & \\
\hline $\mathrm{P} 1$ & \multicolumn{5}{|l|}{$<0.001 * *$} \\
\hline $\mathrm{P} 2$ & \multicolumn{5}{|l|}{0.51} \\
\hline
\end{tabular}

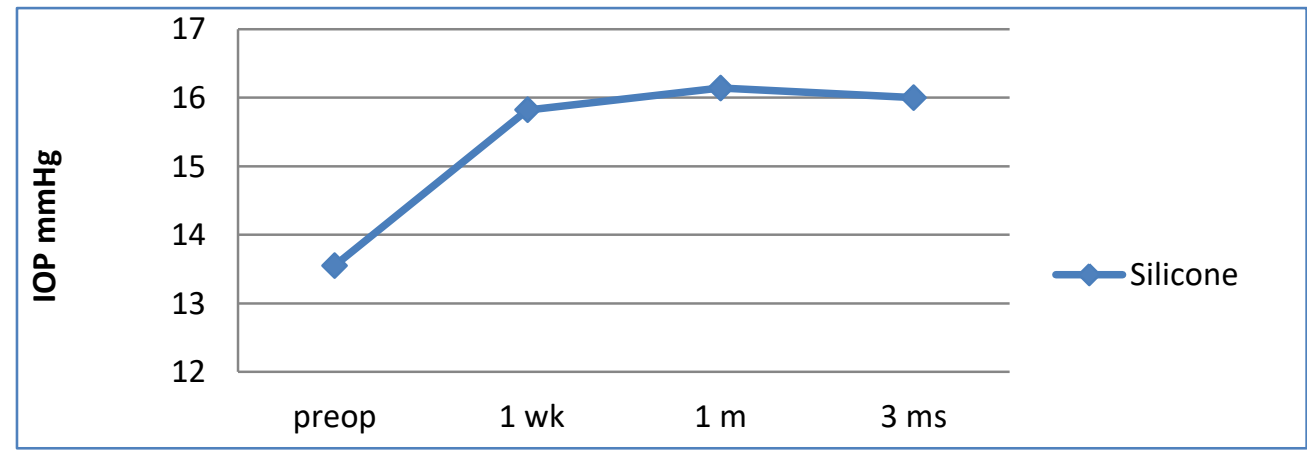

(Fig. 2): IOP changes over the 3-months follow-up period. 


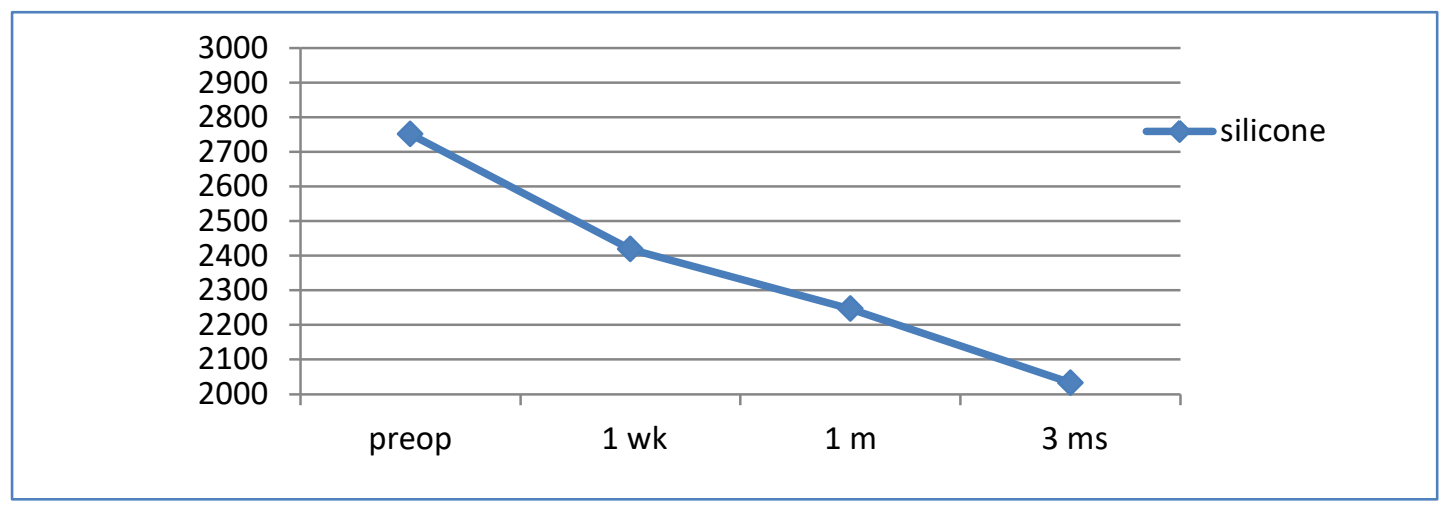

(Fig. 3): Mean ECD over the 3-months follow-up period

\section{DISCUSSION:}

Corneal endothelial cell (EC) loss can result from age, systemic diseases, trauma or ocular surgery. Corneal endothelial cells are not regenerated once damaged with lack of cell proliferation resulting in reduction in ECD ${ }^{[9]}$. Endothelial cell damage can induce corneal decompensation which is one of the reported corneal complications following vitreoretinal surgery and is a common cause of poor visual outcomes following an otherwise successful surgery ${ }^{[1]}$. Many factors for postoperative endothelial cell loss have been reported after vitreoretinal surgery, including silicone oil used as tamponade, IOP fluctuation, phototoxicity, irrigation solution turbulence, $\mathrm{pH}$, and temperature changes ${ }^{[10]}$.

This study included 27eyes (17 right and 10 left eyes) of 27 patients, 14 were females and 13 males. Patients were schedueled for pars plana vitrectomy with silicone oil injection, held in ophthalmology department, Zagazig University Hospitals for different causes as shown in Fig 1. SO was retained in vitreous cavity throughout the whole followup period (3 months) without being removed or detected in anterior chamber. The mean age \pm SD was $54.6 \pm 8.7$ years. The baseline preoperative mean endothelial cell count was $2751.25 \pm 442.75$ cells $/ \mathrm{mm}^{2}$.

The following parameters were evaluated in the current study preoperatively, one week, one month and three months postoperatively: Endothelial cell count (ECD), Coefficient of Variation (CV), percentage of Hexagonal cells (HEX) and central corneal thickness (CCT).

Endothelial cell count was significantly affected after pars plana vitrectomy. The mean preoperative endothelial cell count decreased from 2751 cells $/ \mathrm{mm}^{2}$ to 2032cells $/ \mathrm{mm}^{2}$ at 3 months postoperatively (Pvalue $<0.001)$. The percentage of mean endothelial cell loss after PPV with SO injection was about $12 \%, 18.34 \%$ and $26.1 \%$ on 1week, 1month, and 3 months postoperatively, respectively indicating statistically highly significant endothelial cell loss as shown in Tables $6 \& 7$.

Eyes that had undergone previous cataract surgery were more vulnerable and hence more prone to EC loss than phakic eyes ${ }^{[10]}$. In our study in order to identify effect of previous cataract surgery on corneal endothelium, ECD changes over the 3-months follow-up period according to lens status were estimated and compared between both phakic patients (who remained phakic throughout the follow-up period) and pseudophakic patients (who performed uneventful phacoemulsification at least 6 months before PPV). EC loss over the 3-months follow-up period was highly significant $(\mathrm{p}<0.001)$ in both groups and percent of EC loss was $17 \%$ and $21.8 \%$, in phakic and pseudophakic patients respectively. However, the difference in endothelial cell loss between both groups was statistically insignificant as in Table 11.

Cinar et al, $2015^{[10]}$ evaluated corneal endothelial cell (EC) damage after 


\section{Sara et al..}

vitreoretinal surgery using different tamponades; gas (SF6) or SO and compared the results. A final conclusion was made that PPV with gas (SF6) or SO endotamponade resulted in a significant decrease in EC. They reported that the median EC count loss in (SF6 gas) group and (SO) group was statistically different at baseline vs 3 months postoperatively (all $\mathrm{P}<0.05$ ). The percentage of changes in MCD at 3 months after PPV were $3.8 \pm 2.8 \%$ in SF6 group, and $4.6 \pm 5.4 \%$ in SO group, respectively. According to lens status, they also showed mean EC loss of $3.8 \%$ in phakic and $8.0 \%$ in pseudophakic eyes and hypothesized that the lower EC loss in phakic patients might be due to the protective effect of the intact lens.

At 6 months of follow up, Farrahi et al, $2014^{[18]}$ revealed that the presence of SO in the vitreous cavity of phakic and pseudophakic eyes has no statistically significant effect on ECD but has a significant effect on hexagonality $(\mathrm{P}=0.004)$ and $\mathrm{CV}$ $(\mathrm{P}=0.003)$. The EC loss even if was not statistically significant but was remarkable.

Goezinne et al, 2014 ${ }^{[19]}$ stated that less than 5\% EC loss at 12monthsfollow-up period after PPV with SO tamponade for complex RRD was found in Group 1 (phakic eyes) and Group 2 (pseudophakic eyes). The study also stated that there wasn't any significant difference in CV nor in HEX that pointed to the absence of wound healing despite high EC losses and suggesting that EC function might not be altered.

A prospective study on ECD after PPV without SO tamponade, Friberg et al, $1984^{[20]}$ reported a significant ECD reduction in aphakic eyes $8.5 \%$ and no EC loss in phakic eyes undergoing PPV.

Friberg and Guibord $1999^{[21]}$ showed that retained $\mathrm{SO}$ in the vitreous body contributed significantly to EC loss. Mean EC loss was $69 \%$ in 10 eyes with retained SO after a mean postoperative follow-up of 10 months compared with the fellow eye as control. They stated a major conclusion that EC loss after vitreoretinal surgery might increase further because of the long-term SO retention. In the same study pseudophakic eyes had a $52 \%$ EC loss.
Rosenfeld et al, $1986^{[22]}$ reported a reduction of ECD at 6 months postoperatively in phakic eyes $(0.4 \%)$ compared with aphakic eyes (13\%). They posed the idea that higher EC losses may be because of the use of SO.

Regarding other corneal parameters, the coefficient of variation (CV) represents the degree of polymegathism which reflects the process of wound healing as the cells enlarge to maintain apposition and cover the posterior corneal surface completely ${ }^{[23]}$. In this study, the overall changes in $\mathrm{CV}$ (polymegathism) were not statistically significant. They were independent from endothelial cell count and were inversely related to each other. CV increased by 1 week and 1month postoperatively to start to nearly stabilize by 3 months postoperatively as in Table 8.

Endothelial morphology is the best indicator of corneal endothelial stress or instability and as a general rule stressed corneas have HEX $<45 \%$ and/or CV $>45 \%$. Endothelial cell density changes indicated cell damage that has already occurred and EC morphology represents ongoing corneal EC stress or instability. The size and shape of corneal ECs provides information on the injury and function ${ }^{[24]}$.

In this study, the overall changes in percent of hexagonal cells HEX (pleomorphism) were statistically significant over the 3-month follow up period with mean percent decrease $3.82 \%$ as shown in Table 9.

Measurement of corneal thickness is useful for assessing the extent of surgical stress following vitrectomy ${ }^{[25]}$. In our study CCT was measured by non-contact specular microscopy preoperatively, 1 week, 1 month and 3 months postoperatively. We found that there were no statistically significant changes over the 3-month follow up period. The mean central corneal thickness remained nearly the same throughout the study as in Table 10.

Buch et al, $1999^{[26]}$ measured CCT by ultrasonic pachymetry for two groups; with $\mathrm{SO}$ as vitreous substitute (group 1) and with other substitution materials as gas, air or saline (group 2). Measurements were performed preoperatively and 24 hours, 48 hours and 5 months postoperatively. Increase of CCT of the affected eyes was found in both groups with the peak increase in CCT 
Sara et al..

appeared 24 hours postoperatively in the nonsilicone group $(13.9 \%)$ while the peak increase in CCT of the silicone group appeared 48 hours postoperatively (14.1\%). Five months post operatively the mean CCT decreased and returned to CCT baseline value in both groups. Evaluation of CCT differences between both groups at any time point showed no significant difference. Abrams et $\boldsymbol{a l}, \mathbf{1 9 9 5}^{[27]}$ showed similar results as Buch $\boldsymbol{e t}$ $\boldsymbol{a l}, 1999$ in eyes treated with silicone oil and C3F8.

Watanabe et al, 2012 $2^{[28]}$ measured CCT by pentacam for 20 eyes that had undergone PPV with SO injection. CCT was measured prior to as well as following 1 week, 1 month, and 3 months after surgery. Postoperative data showed a significant increase at 1 week after surgery, but recovery to preoperative levels was evident only 1 month after surgery. No significant differences in thickness were apparent between preoperative measurements and at 3 months after surgery.

Diabetes mellitus is an additional risk factor affecting the endothelium by its induced metabolic stress. Patients with DM have lower mean cell count, thicker corneas with greater pleomorphism and polymegathism when compared to healthy individuals ${ }^{[29]}$.

Chung et al, 1988 ${ }^{[30]}$ and Hiraoka et al, $2001^{[31]}$ stated that in diabetic patients, high incidences of corneal complications after vitrectomy have been reported. These complications were often resistant to ordinary therapy and require long-term treatment. They assumed that corneal complications after vitrectomy in diabetic patients take place more than non-diabetic patients due to intraoperative damage combined with preexisting subclinical corneal abnormalities.

In our study, ECD changes in diabetic and non-diabetic patients were estimated showing highly significant EC loss $(p<0.001)$ in diabetic and non-diabetic patients without significant difference in EC loss between them as shown in Table 12.

High IOPs in the first 24 hours postoperatively add additional damage to the newly injured corneal endothelium ${ }^{[32]}$. High IOPs, even if they existed for a minimum of 3 days, lowered the central ECD significantly [33]

As regards IOP assessment during our study, there was highly significant increase in IOPfrom the preoperative values after 3 months follow-up period with mean increase $2.45 \pm 0.73 \mathrm{mmHg}(2.16 \%)$. The main increase in IOP values was in the $1^{\text {st }}$ week postoperatively by $2.14 \%$. The cut-off value above which IOP was considered high and requiring antiglaucoma was $25 \mathrm{mmHg}$ and none of our patients have reached IOP above $25 \mathrm{mmHg}$ or received antiglaucoma medication. (Table 5)

Buch et al, $1999^{[26]}$ reported an increase in IOP 48 hours post operatively. IOP increased by a mean value $3.0 \mathrm{mmHg}(20.2 \%)$ in the silicone group. Five months post operatively; IOP had regained normal value. Changes in IOP did not differ significantly between both groups at any time point.

\section{CONCLUSION}

Pars plana vitrectomy is associated with corneal endothelial cell changes in the form of EC loss and pleomorphism. Silicone oil could be a risk factor for increasing endothelial cell loss after pars plana vitrectomy. The percentage of corneal endothelial cell loss was statistically highly significant in patients with SO injection.

Our study had some limitations. The enrolled patients were only followed for 3 months. Thus, a long-term study is needed with EC counts to be measured at consecutive follow-up visits. One should further keep in mind that EC losses may be even higher if patients were followed for a longer time period. Also, the relatively low number of patients hence results may be more significant when more patients are included in the study thus, more patients should be enrolled in future studies. In addition, the imbalance between the indications for PPV surgery may also have an indirect effect on EC loss; because patients with complex retinal detachment probably have required longer surgery times.

\section{REFERENCES}

1. Paris MP, Peyman GA, Kao GW. Early anterior segment complications after silicone oil injectio. Can J Ophthalmol. 1986; 21: 271-275. 
2. Machemer R, Buettner $\mathbf{H}$, et al. Vitrectomy: a pars plana approach. Trans Am Acad Ophthalmol Otolaryngol.1971;75:813820.

3. Karel, I. Indications for pars plana vitrectomy. Ceskoslovenska oftalmologie. 1989; 45: 65-70.

4. Olteanu, M., and D. Stanciu. Indications and contraindications of vitrectomy and technical methods used after the initial months of clinical experience. Revista de chirurgie, oncologie, radiologie, orl, oftalmologie, stomatologie. Seria: Oftalmologie. 1984:28: 113-116.

5. Peyman GA, Schulman JA. Appleton \& Lange, East Norwalk Connecticut, USA. Vitreous Substitutes. 1995 A comprehensive review of the early history of vitreous substitute development

6. Cibis PA, Becker B, Okun E,et al. The use of liquid silicone in retinal detachment surgery. Arch Ophthalmol. 1962; 68:590599.

7. Scott I, Flynn H, Murray T, et al. Outcomes of complex retinal detachment repair using 1000- vs. 5000-centistoke silicone oil. Arch Ophthalmol. 2005; 123:473-478.

8. Lai JC, Stinnett SS, McCuen BW. Comparison of silicone oil versus gas tamponade in the treatment of idiopathic full thickness macular hole. Ophthalmology. 2003; 110:1170-1174.

9. Ko MK, Park WK, et al. A histomorphometric study of corneal endothelial cells in normal human fetuses.Exp Eye Res. 2001; 72: 403-409.

10. Cinar $\mathbf{E}$, Zengin $\mathbf{M}$ and Kucukerdonmez $\mathbf{C}$ : Evaluation of corneal endothelial cell damage after vitreoretinal surgery: comparison of different endotamponades. Eye (Lond) 2015; 29: 670-674

11. Green K, Cheeks $\mathbf{L}$, et al. Role of toxic ingredients in silicone oils in the induction of increased corneal endothelial permeability. Lens Eye Toxic Res. 1992; 9: 377-338.

12. Choi WC, Choi SK \& Lee JH. Silicone oil keratopathy. Korean J Ophthalmol. 1993;7, 2: 65-69.

13. Jacobiec FA \& Front RL. Orbit. In: Spencer WB, ed. Ophthalmic Pathology: an atlas and textbook. 3rd ed. Philadelphia. Saunders, 1986:1148-1154.

14. Federman $\mathbf{J}$ and Schubert $\mathbf{H}$. Complications associated with the use of silicone oil in 150 eyes after retina-vitreous surgery. Ophthalmology.1988;95:870-876.

15. Munirul SM, Vazeen M. "Post Operative Complications." Cataract Surgery and Phacoemulsification for the Beginning Surgeons. AuthorHouse, 2014.

16. Domniz YY, Cahana M, Avni I. Corneal surface changes after pars plana vitrectomy and scleral buckling surgery.J Cataract Refract Surg. 2001;27:868-72.

17. Okamoto F, Okamoto C, Sakata N, et al. Changes in corneal topography after 25gauge transconjunctival sutureless vitrectomy versus after 20-gauge standard vitrectomy.Ophthalmology. 2007;114:213841

18. Farrahi F, Feghhi M, Ostadian F, et al. Pars Plana Vitrectomy and Silicone Oil Injection in Phakic and Pseudophakic Eyes; Corneal Endothelial Changes. J Ophthalmic Vis Res. 2014;9:310-3.

19. Goezinne F, Nuijts R, Liem A, Et al: Corneal endothelial cell density after vitrectomy with silicone oil for complex retinal detachments. Retina. 2014; 34: 228236.

20. Friberg TR, Doran DL, Lazenby FL. The effect of vitreous and retinal surgery on corneal endothelial cell density.Ophthalmology 1984; 91: 11661169.

21. Friberg $\mathbf{T}$ and Guibord $\mathbf{N}$. Corneal endothelial cell loss after multiple vitreoretinal procedures and the use of silicone oil. Ophthalmic Surg Lasers. 1999;30:528-534

22. Rosenfeld SI, Waltman SR, et al. Comparison of intraocular irrigating solutions in pars plana vitrectomy.Ophthalmology. 1986; 93: 109115.

23. Al-Sharkawy HT. Corneal endothelial changes in type 2 diabetes mellitus before and after cataract surgery. Journal of the Egyptian Ophthalmological Society. 2015;108:79

24. Meyer L, Ubels $\mathbf{J}$ and Edelhauser $\mathbf{H}$. Corneal endothelial morphology in the rat. Effects of aging, diabetes, and topical aldosereductase inhibitor treatment. Invest Ophthalmol Vis Sci. 1988;29:940-948

25. Wood $W$ \& Maumenee AE. Cornealthickness after cataract extraction. TransAm Acad Ophthalmol Otolaryngol. 1975; 79: 631. 
26. Buch, H., Nielsen, N. V. , et al. Pachometry before and after vitrectomy with silicone oil injection. Acta Ophthalmologica Scandinavica. 1999;77: 410-413.

27. Abrams G, Azen SP, Barr CC, et al."The incidence of corneal abnormalities in the silicone study: Silicone study report 7". Arch Ophthalmol.1995;113: 764-769.

28. Watanabe, Akira, et al. Changes in corneal thickness following vitreous surgery. Clinical ophthalmology (Auckland, NZ). 2012; 6: 1293.

29. Lee JS, Oum BS, Choi HY, et al. Differences in Corneal Thickness and Corneal Endothelium Related to Duration in Diabetes. Eye. 2006; 20:315-18.
30. Chung H, Tolentino FI, Cajita VN, et al. Reevaluation of corneal complications after closed vitrectomy. Arch Ophthalmol 1988;106:916-9.

31. Hiraoka M, Amano S, Oshika T, et al.

Factors contributing to corneal complications after vitrectomy in diabetic patients.

Japanese journal of ophthalmology. 2001;45:492-495.

32. Ko YC, Liu CJL, Lau LI, et al. Factors related to corneal endothelial damage after phacoemulsification in eyes with occludable angles. J Cataract Refract Surg. 2008;34:4651

33. Setala K. Corneal endothelial cell density after an attack of acute glaucoma. Acta Ophthalmol (Copenh). 1979;57:1004-1013. 